\title{
Sources of Conflict in a Bi-national Organisation: A Case Study of Tanzania Zambia Railway Authority (TAZARA)
}

\author{
Mwansa Kamukwamba \\ Mulungushi University, Kabwe, Zambia
}

This study explores sources of conflict in Tanzania Zambia Railway Authority: a bi-national organization jointly owned and managed by two contracting states of the Republic of Tanzania and the Republic of Zambia—countries with different historical, political, economic, and social backgrounds. Tanzania Zambia Railway was constructed and funded by interest free loan from the People’s Republic of China. The importance of this study comes from recent economic and political developments signaling the advent of globalization where countries are forming regional, political, and economic groupings. Such countries in Europe have formed a regional, political, and economic grouping called European Union (EU); countries in Africa have also formed their political and economic grouping called African Union (AU); so have countries in Asia. African countries have also formed economic communities such as Southern Africa Development Community (SADC), East African Community (EAC), and Economic Community for West African States (ECOWAS), while the United States of America (USA) and South American countries have signed an economic agreement called North American Free Trade Agreement (NAFTA) and Asia Pacific Economic Co-operation (APEC) in Asia. All these economic communities and agreement are intended to eliminate economic barriers between them. It is envisaged that these developments will lead to adopting bi-national organizations as common forms of business organization (such as Euro Tunnel between France and the United Kingdom), hence the need to identify sources of conflict in such organizations. The study is intended to answer such questions-What is a conflict? What would be the sources of conflict in a bi-national organization? How would conflicts be resolved in a bi-national organization? How does conflict affect actors in the organization? Does conflict affect organization performance? Conflict is defined as a total range of behavior and attitude that express opposition and divergent orientations perceived as both rational and inevitable. It results from organizational and industrial factors (structurally determined) and defined rolls of actors. The study was guided by phenomenological paradigm focusing on sources of conflict in a bi-national organization. Phenomenological paradigm was appropriate due to the nature of inquiry. Sources of conflict are concerned with the relationships of the three actors: employee, employer, and the government. This paradigm provides the opportunity to explore sources of conflict as an academic discipline. TAZARA as an organization, the government as both an institution and employer, and employees as both individuals and groups. The paper was designed as a case study deeply rooted in phenomenological paradigm where the researcher explores the case (in this case) of conflict and Tanzania Zambia Railway Authority as the institution. Primary data were collected from focus groups discussions and

Mwansa Kamukwamba, Dr., lecturer in Human Resource Management and Industrial Relations, Mulungushi University, Kabwe, Zambia.

Correspondence concerning this article should be addressed to Mwansa Kamukwamba, School of Business Studies, Mulungushi University, P.O. Box 8415, Kabwe, Zambia. 
structured interviews, both of which were taped to facilitate data analysis and questionnaires while secondary data were collected from organization records, reports, books, news papers, and consultant reports. Data were analyzed using triangulation and qualitative techniques. Sample size comprised of eight Government and Board of Directors officials, 35 Management officials, 16 Trade union officials, and 64 Focus group members from eight discussions groups, brings the total to 123 . The study revealed that conflict is generated by many sources which are grouped into two groups: those generated by differences of national economies and those generated by differences of legal systems. These differences are as a result of the two countries' differences in cultural, social, political, and economic backgrounds of the two contracting states. The study further revealed that so far the organization has put in place conflict resolution systems and therefore has been able to settle conflict harmoniously. This is a clear indication that actors in a bi-national organization should be sensitive to each other's concerns only then will they be able to identify sources of conflict and put in place effective conflict resolution systems.

Keywords: bi-national organization, conflict, phenomenological paradigm, case study, triangulation

\section{Introduction}

In order to grasp the significance of identifying sources of conflict in Tanzania Zambia Railway Authority (TAZARA) — a railway organization jointly owned and managed by Governments of the United Republic of Tanzania in East Africa and the Republic of Zambia in Southern Africa and to increase their independence, it is important to explore the role which railways played in opening up countries during colonial era. The development of the railway system in Tanzania and Zambia puts the identification of sources of conflict in Tanzania Zambia Railway Authority in perspective and makes it easy to appreciate Presidents Nyerere of Tanzania and Kaunda of Zambia's determination to construct the railway link from the port of Dar-es-Salaam to the Copper belt in Zambia (Bailey, 1976; Hall \& Peyman, 1979).

The idea of building a railway in Northern Rhodesia (now Zambia) was not known, and it was part of the imperial plan of the diamond magnate John Cecil Rhodes of building a railway from Cape in South Africa to Cairo in North Africa (Bailey, 1976; Hall \& Peyman, 1976). According to imperialists, the construction of a railway was determined by the availability of raw materials and the market of manufactured goods. Rhodes's plan was to link Cape Town in South Africa to Cairo through either Tanganyika (now Tanzania) or Congo Free State (now Democratic Republic of Congo or Congo DR), then Sudan another British Colony and to Cairo in Egypt.

Berlin Conference which determined the partition of Africa in 1884 recognized Tanganyika and Congo Free State as Germany and Belgium Colonies respectively. The same Conference recognized a railway as a sign of effective occupation as Hall and Peyman (1976) pointed out thus, the term "Permanent Way". This frustrated Rhodes's plan because neither Belgiaum nor Germany would allow a railway owned by another imperial power to pass through its territory.

In Northern Rhodesia, the availability of minerals determined the construction of the railway, while in Tanganyika the construction was determined by trade and commercial farming in coffee and sisal. Germans constructed the first railway from Tanga their administrative center to interlard in 1891 (Gwassa \& Illife, 1969; Mihyo, 1979).

There are differences and similarities which have influenced sources of conflict between the two contracting states. The similarities include: both countries were colonized, in case of Tanganyika first, by 
Germany and then by Britain making Tanganyika the only country colonized by two colonial powers in East Africa; yet both countries were granted independence by Britain and therefore inherited British national institutions and political economy; both countries have national trade unions. Differences include: the two colonies pursued different national ideologies when they became independent. Tanzania adopted Socialism while Zambia adopted Humanism. These ideologies dictated these countries' political economies. The two countries have different economic bases: Tanzania being basically an agricultural country, while Zambia is dependent on the mining industry, which also dictates workers' wages as the Government and the mining industry would rather favorably consider mineworkers' salary demands than risk workers' industrial action which would affect copper production and subsequently the national economy.

This paper argues that a bi-national organization should recognize the fact that each country has its interest, objectives, and leadership both formal and informal, whose reconciliation is a recipe for conflict. Identification of sources of conflict is crucial in helping put in place systems of managing conflict when it arises.

The study identified the following main sources of conflict:

(1) Conflict caused by different economies.

(2) Conflict caused by different legal systems.

Conflict caused by different economies:

(i) Salaries and the foreign exchange rate mechanism.

(ii) Inter-territorial allowance.

(iii) National pension schemes.

Conflict caused by different legal systems:

(i) Collective bargaining procedures.

(ii) Trade union consultation procedures.

(iii) Disciplinary code and procedures.

\section{Conflict Caused by Different National Economies}

\section{Salaries and the Foreign Exchange Rate}

The first challenge which TAZARA management faced was from the dominating effects of global forces on exchange rates (Smith \& Meiksin, 1995). These had to be fixed so that salaries paid to Tanzanian and Zambian workers would reflect the principle of equal work and equal pay. In 1976 the Council of Ministers fixed the exchange rate for salaries at 1 Zambian Kwacha to 10 Tanzanian Shillings (Tshillings). At the time 1 Zambian Kwacha was equal to $£ 1$ sterling and therefore stronger than the TShilling, which was worth only half that amount.

In the 1980s Zambian copper prices started declining on the London Metal Exchange and this affected the Zambian foreign control regulations; consequently the Zambian Government started floating the Zambian Kwacha while the Tanzanian government continued using their foreign exchange control mechanism. The result was that the Zambia Kwacha depreciated against the TShilling. This led eventually to the 1991 report on salary disparity (Tanzania Zambia Railway Authority, 1991). The disparity was defined as the difference between salaries paid to workers in Tanzania and salaries paid to workers in Zambia, resulting from foreign exchange fluctuations.

In November 1990 the Railway Workers' Union of Zambia (RWUZ, the precursor of WUTAZ) had made a strong representation to management that TAZARA salaries were denominated in US dollars. The union 
argued that the bi-national nature of the railway justified this arrangement and that inflation in Tanzania and Zambia has operated so differently over the past few years so that only a hard currency could represent a stable measure of the real value of the salaries paid to the authority's employees in the two countries. TAZARA management suggested that salaries be denominated in the stronger of the two countries, which at the time was the TShilling. JUWATA, the Tanzanian trade union, objected to this suggestion and demanded that salaries be denominated in US dollars as originally proposed by RWUZ. TAZARA management recommended to TAZARA Board of Directors that salaries be denominated in US dollars, but the Board rejected the recommendation on the grounds that the proposal was not the only solution to the disparity problem and directed a thorough investigation into the real causes of the disparity in order to propose a permanent solution. The Committee constituted to carry out the investigation reported that there was no clear-cult salary policy in TAZARA and that the fixing of the exchange rate at 1 Kwacha to 10 Shillings was arbitrary, as there was no direct exchange rate between the Kwacha and the Shilling and therefore the purchasing power of neither currency was influenced by the exchange rate between them. The Committee, however, confirmed the existence of the disparity between Tanzania and Zambian salaries and recommended that all salaries be denominated in US dollars. TAZARA accepted the recommendation in 1991.

TAZARA workers seemed to be content with this arrangement although some union officials were of the opinion that salaries should be based on the food basked, i.e., how much the worker could buy with his salary, not on mere figures. However, the food basket proposition proved to be unrealistic because of the two countries' different political and economic systems.

\section{Inter-Territorial Allowance}

The inter-territorial allowance is defined as an allowance of 55\% of an employee's monthly salary paid to employees who have been posted to work in another country. It is paid to Zambian employees working in Tanzania, at Head Office in Dar es Salaam and Mbeya Workshops, and to Tanzanians working at TAZARA Training School at Mpika in Zambia.

When the railway became operational, TAZARA Management noted that most of the Zambian positions at the Head Office and TAZARA Training School were vacant because of the poor salaries, and suggested to the Board of Directors that an allowance be introduced to induce Zambians to join TAZARA. The Board recommended this to the Council of Ministers, which approved 55\% as inter-territorial allowance.

This allowance has divided TAZARA workers into national camps. Most Tanzanians are of the view that this allowance should be abolished because the situation has changed, as Zambians are now willing to work for TAZARA at both Mbeya and Head Office, while Zambians argue that the allowance should continue because when one is away from one's home country the job is the only source of livelihood, whereas a national worker can find other sources of income. During the study Zambian Kwacha was weaker than Tshillings, giving an advantage to Zambians who bought more Kwacha for their Tshillings.

The study however revealed that the allowance has not solved the recruitment problem as most Zambian positions at Head Office and Mbeya are filled through internal promotion of TAZARA employees, or they are vacant waiting to be filled: an indication either that salaries in TAZARA remain unattractive to the Zambia labour market or that there are other factors such as the remoteness of the area through which the railway passes. The study also noted that most Zambian, either at Head Office or Mbeya, who have been retained by TAZARA were directly recruited from learning institutions. It has therefore, been suggested that TAZARA 
should concentrate on recruiting workers direct from learning institutions and develop them within the organization.

\section{National Pension Schemes}

When TAZARA started operations, workers were members of their national pension schemes; their contributions were supposed to be remitted by TAZARA (their employers) to national insurance companies which ran the national pension schemes. However, their membership was withdrawn due to TAZARA's failure in remitting the contributions. Since TAZARA Act provides for the establishment of its own pension scheme, TAZARA decided to establish one, but this also collapsed due to non-remittance of contributions to its own scheme.

The Tanzanian Government has launched a National Social Security Fund Pension Scheme to which all employees should belong. Both employees and employers contribute $10 \%$, giving total pension benefits of $20 \%$. The Zambian Government has also launched a National Pension Scheme for all employees, with employees and employers contributing $5 \%$ each, with total pension benefits of $10 \%$.

The implications of these schemes are that the same organizations will be contributing double the percentage towards Tanzanian as Zambian workers' pensions. The trade union in Zambia is proposing to establish a TAZARA Pension Scheme as provided for in the Act, but the trade union in Tanzania seems to be reluctant to support such a proposal for two reasons: First, contributions should not be so high that they affect the take-home pay, or lower than $10 \%$ which will reduce their pension below the national level. Second, the scheme may collapse again due to TAZARA's inability to remit contributions.

The Council of Ministers and the Board of Directors may consider raising Zambian workers' pension contributions to $10 \%$ to equate them to Tanzanian contributions.

Thus the onus is on TAZARA as an organization to either establish its own pension scheme as provided by the Act, or adjust contributions to a level acceptable to both countries and ensure that the scheme is maintained.

\section{Conflict Caused by Different Legal Systems}

\section{Collective Bargaining Procedures}

This case illustrates conflict which may arise as a result of different labour laws.

Zambia region was the first to start negotiating for their members' conditions of employment, having established a trade union and then a Joint Industrial Council. The first RWUZ and TAZARA Management Joint Industrial Council (JIC) met in 1982. Members of JUWATA, the Tanzanian trade union, attended as observers since both TAZARA Management and RWUZ accepted them as members of a trade union despite the country's labour laws not formally allowing their trade unions to negotiate for their members' conditions of employment.

However, JUWATA attendance raised a legal concern when the Collective Agreement was referred to the Zambian Commissioner for Labour for approval. It was noted that there were two trade unions: RWUZ for Zambia and JUWATA for Tanzania, and that the Agreement cited two Acts: the Zambian Industrial Relations Act Cap 517 of 1971 and the Tanzanian Security of Employment 1964 Act (Collective Agreement between TAZARA Management and RWUZ, 29 January, 1982).

The Commissioner for Labour in Zambia rejected the Agreement on the grounds that:

(a) It incorporated facts or material alien to the Zambian situation. 
(b) The inclusion of JUWATA as a subscribing party to the Agreement was not only unacceptable but contrary to the current industrial relations laws in the country.

(c) The majority of the provisions of the Agreement were contrary to the provisions of the industrial relations scene in Zambia and therefore the Agreement should make provisions which were legally enforceable in Zambia.

With those remarks the Agreement was referred to the Industrial Relations Court directed in May 1982 that the parties to the Collective Agreement should re-negotiate the Agreement and that it should take account of laws and practice only in Zambia. The Agreement was re-negotiated and submitted and eventually approved for a period of one year, effective from 1 January 1984. Subsequent Collective Agreements are divided into periods; conditions of service are reviewed after two years while salaries are reviewed annually, a provision for annual exchange rate fluctuations.

The Zambian Commissioner's Labour rejection of the first Agreement highlighted the importance of the two trade unions and TAZARA Management working within the laws of each contracting state, and it raised further questions. If the Agreement was confined to the labour laws of one country, should its implementation be confined to the members of that country's trade union? The Council of Ministers resolved that the Agreement should be implemented throughout the system including JUWATA members in Tanzania Region. The whole system implementation introduced another problem: the cost of the Joint Industrial Council (JIC). RWUZ argued that their members subscribed to the costs of JIC, but questioned whether they should continue subscribing to it if the Agreement was extended to the members of JUWATA in Tanzania Region. The Council of Ministers directed TAZARA Management to fund JIC until such time as the trade unions in Tanzania were allowed to negotiate with management and therefore were able to fund their JIC meetings.

The case illustrates two important points: first the importance of the two trade unions working within the labour laws of the two contracting states; and second the power invested in the Council of Ministers to deal with the organization's internal problems.

\section{Trade Unions Consultation Procedures}

In 1983, JUWATA and RWUZ signed a memorandum of understanding that the two trade unions could consult each other as and when the need arose. Consultations are scheduled for at least three times a year or whenever deemed necessary. Consultation issues include: conditions of employment, review of salaries, and disciplinary code and procedure. In Tanzania, the disciplinary code and procedure is provided for in the Security of Employment 1964 Act and therefore is regarded as "given", while in Zambia it has to be negotiated through collective bargaining (Industrial Relations Act, 1971). At one of these consultative meetings, RWUZ came to learn that though both regions were using the same Collective Agreement (signed by TAZARA Management and RWUZ). JUWATA, a Tanzanian trade union, was not party to the Agreement because members attended the meeting as observers only not as participants because Tanzanian labour laws did not allow trade unions to negotiate conditions of services for their members as trade unions in Tanzania were regarded as Government representatives and therefore were used as conveyer belts by government to convey government information to workers (see conflict caused by different legal systems above). Tanzania Region did not apply the disciplinary code and procedure that was part of the Agreement but instead applied the one provided by the Security of Employment Act 1964. RWUZ wrote a letter of protest to TAZARA Management demanding an explanation. 
That TAZARA Management reply to this protest was long, but centered on the fact that there was very little if anything TAZARA could do about this since the disciplinary code and procedure in Tanzania is part of the Employment Act and not subject to collective bargaining procedures.

This revelation highlights the vulnerability of both management and trade unions to the countries' labour laws. There was nothing any of the parties to the Collective Agreement could do. TAZARA Management could not apply the disciplinary code in the Collective Agreement between TAZARA and RWUZ because if the employee took them to the Tanzanian Court it would not recognize the code and its procedures; at the same time TAZARA Management in Tanzania had no basis for defending the Collective Agreement, to which they were not a party. Consequently, employees in Tanzania had the advantage of enjoying conditions of employment in the Agreement without being penalized under the disciplinary code and procedures of the same Collective Agreement.

This case, more than any other taught the two trade unions to work within the labour laws of the two contracting states.

\section{Disciplinary Code and Procedure: Lubinda and Others VS TAZARA}

In the 1980s both Tanzania and Zambia, for various political and economic reasons, started experiencing economic crises (Debrah, 2004; Larmer, 2002; Turner, 1992) and therefore needed financial assistance from the I international Monetary Fund (MF) or the World Bank for their economic structural adjustment programmes.

Although TAZARA was not directly involved in getting financial assistance from these institutions it was operating in a hostile economic environment, in which both Tanzania and Zambia needed financial assistance. Consequently, the TAZARA Council of Ministers decided to reduce operational costs by declaring $15 \%$ of the TAZARA labour force redundant at the Head Office in Dar es Salaam, and in Tanzania and Zambia Regions. The redundancies were supposed to be implemented in accordance with the labour laws of the respective country. However, in Tanzania the Council of Ministers' decision led to the case of Lubinda and Others VS TAZARA.

According to Lubinda and 183 Others VS TAZARA case records (1990) Tanzanian labour laws provided for management to inform the trade union, in this case JUWATA, of their intention to declare employees redundant. Tanzania Regional Management complied and laid off 15\% of the total establishment in the Tanzania Region. However, in the Zambia Region the Industrial Relations Act 1971 provided that any redundancy should be discussed between management and the trade union and therefore the Collective Agreement should provide for a redundancy clause. Consequently, the first Collective Agreement between TAZARA and RWUZ had a redundancy clause stipulating the procedure to be followed when a redundancy was contemplated. When Zambia Region Management contacted the trade union to fulfill the Collective Agreement procedures on how to effect the $15 \%$ redundancies in the region, the two groups could not agree. The trade union rejected declaring workers in Zambia redundant, arguing that the personnel establishment was only $45 \%$, effecting redundancy would leave the establishment at 30\%, and making TAZARA operations impossible. According to Zambian law, redundancy could only be effected if both trade union and management agreed. Since Zambia Regional management failed to convince the trade union, redundancy could not be carried out in Zambia Region.

Learning that in the Zambia Region the trade union had refused to declare workers redundant, employees who had been declared redundant in the Tanzania Region complained through the Legal Aid Committee to the 
Minister of Labour, who nullified the decision of the Management. Finally the Minister's findings were upheld by the Tanzania Court of Appeal, giving rise to re-instatement of 116 employees with full entitlements. However, investigation revealed that the Security of Employment 1964 Act provides for negotiations between trade union and management, not simply informing the trade union as the Tanzania Regional Management claimed to have done. In this respect, Tanzania Regional Management erred by not following the redundancy procedures.

The court ruling indicated that national institution is more powerful than organizational institutions (TAZARA and a trade union) and that a bi-national organization is vulnerable to the business environment in which it operates. More importantly, the ruling demonstrates the tensions which may arise when there are two national institutions with different interpretations and applications of their labour laws.

\section{Conclusion}

Tanzania-Zambia Railway Authority, a bi-national organization, has unique sources of conflict compared to those found organizations within each contracting state. Thus a bi-national organization has many factors influencing sources of conflict including the following: colonial legacy of the two contracting states as both were colonies. Tanganyika (now Tanzania) was colonized by Germany from the Partition of Africa Conference held in Berlin in 1884 until the defeating of Germany at the end of two World Wars when it was handed over to Britain making Tanganyika the only country in East Africa colonized by two colonial powers, while Northern Rhodesia (now Zambia) was colonized by Britain. The colonial legacies formed the basis of administrative, political, and economic systems which have and continue to influence the generation of conflict through legal management systems and through Tanzanian and Zambian trade unions practices. Global forces is another factor which influences generation of conflict as it dictates economic policies relating to foreign exchange rate mechanism which affects national economies leading to conflict between national actors. Cultural, political, social, and economic differences of the two contacting states also contribute to generation of conflict.

This study has revealed that it is important for actors in a bi-national organization to understand the importance of identifying their differences which will lead them to identify potential sources of conflict which will eventually enable them to not only resolve their conflict peacefully but also put in place effective conflict resolution systems. So far, Tanzania Zambia Railway Authority as a bi-national organization has not only been able to identify potential sources of conflict and resolve conflicts peacefully but has also been able to put in place effective conflict management resolution systems to effectively deal with conflict as and when it arises.

\section{References}

Bailey, M. (1976). Freedom railway: China and the Tanzania-Zambia link. London: Collings.

Debrah, Y. A. (2004). HRM in Tanzania. In K. N. Kamoche, Y. A. Debrah, F. M. Horwitz, and G. N. Muuka (Eds.), Managing human resources in Africa. London: Routledge.

Gwassa, C. K., Illife, J. (1969). Records of the Maji Maji rising. Jouanal of Historical Association of Tanzania. East African Publishing House.

Industrial Relations. (1971). Act of the laws of Zambia. Zambia: Government Printers.

Hall, R., \& Penyman, H. (1979). The great Uhuru railway: China’s showpiece in Africa. London Gollanez.

Larmer, L. (2002). Exploring workers' consciousness in historical perspective: The mine workers' union in post-colonial Zambia. New Socialist Approaches to History Seminar, Institute of Historical Research, 1964-1991.

Lubinda. (1990). Lubinda and 183 others Vs Tanzania Zambia Railway Authority. Inquiry Into Labour Dispute, (3). 
Mihyo, B. P. (1979). Industrial relations in Tanzania. In U. G. Damachi, H. D. Seibel, J. Scheerder, and H. Linden (Eds.), Industrial relations in Africa, 240-272.

Salamon, M. (2000). Industrial relations: Theory and practice (4th ed.). London: Financial Times/Prentice Hall.

Smith, C., \& Meiksin, P. (1995). Systems, society and dominance effects on cross national organisations analysis. Employment and Society, 19(2), 241-267.

Tanzania Zambia Railway Authority. (1991). Report on salary disparity. Dar es Salam: Tanzania.

Turner, T. (1992). Determinants of trade union growth in Zambia Since independence. Employee Relations, 14(2), 55-67. 